\title{
Left atrial appendage flow velocities: assessment by velocity encoded magnetic resonance imaging
}

\author{
Kai Muellerleile*, Arian Sultan, Michael Groth, Daniel Steven, Imke Drewitz, Boris Hoffmann, Gerhard Adam, \\ Gunnar K Lund, Thomas Rostock, Stephan Willems
}

From 2011 SCMR/Euro CMR Joint Scientific Sessions

Nice, France. 3-6 February 2011

\section{Purpose}

To evaluate the use of velocity encoded (VENC) magnetic resonance imaging (MRI) for measurements of left atrial appendage (LAA) flow velocities in comparison with transesophageal echocardiography (TEE).

\section{Introduction}

The presence of reduced LAA flow velocities indicates patients who are prone to thrombus formation in the LAA and therefore being at high risk for subsequent cardioembolic stroke. LAA flow velocities are typically assessed by TEE in clinical routine. VENC-MRI is an established tool for the quantification of transvalvular flow, but the feasibility of LAA flow measurements by VENC-MRI has not been studied so far.

\section{Methods}

The study included 26 patients with sinus rhythm $(\mathrm{n}=15)$ or atrial fibrillation $(n=11)$. All patients underwent VENC-MRI and TEE to assess LAA flow velocities. VENC-MRI was performed perpendicular to the orifice of the LAA to assess through-plane flow. Peak velocities were measured of the passive, early-diastolic LAA outflow (e-wave) in all patients. Peak velocities of active, latediastolic LAA outflow (a-wave) were assessed in patients with sinus rhythm. Figure 1 demonstrates measurements of LAA flow velocities by VENC-MRI in a patient with sinus rhythm. Correlation and agreement was analyzed between VENC-MRI and TEE measurements of e- and a-wave peak velocities and the e/a ratio.

\section{Results}

A good correlation and agreement was found between VENC-MRI and TEE measurements of maximal e-wave velocities $(\mathrm{r}=0.63, \mathrm{P}<0.001$; mean difference $1 \pm 10 \mathrm{~cm} /$ s). The a-wave was detected by VENC-MRI in all patients with sinus rhythm. Correlation was strong for measurements of maximal a-wave velocities between VENC-MRI and TEE $(r=0.73, \mathrm{P}<0.01)$. A mean difference of $10 \pm 16 \mathrm{~cm} / \mathrm{s}$ was found between VENC-MRI and TEE maximal a-wave velocities. There was a good correlation and agreement for the e/a ratio between VENCMRI and TEE $(r=0.63, P<0.01$, mean difference 0.08 \pm 0.12 ).

\section{Conclusions}

The assessment of LAA flow velocities by VENC-MRI is feasible and measurements agree well with TEE. VENCMRI has the potential to identify patients who are at risk for thrombus formation in the LAA.

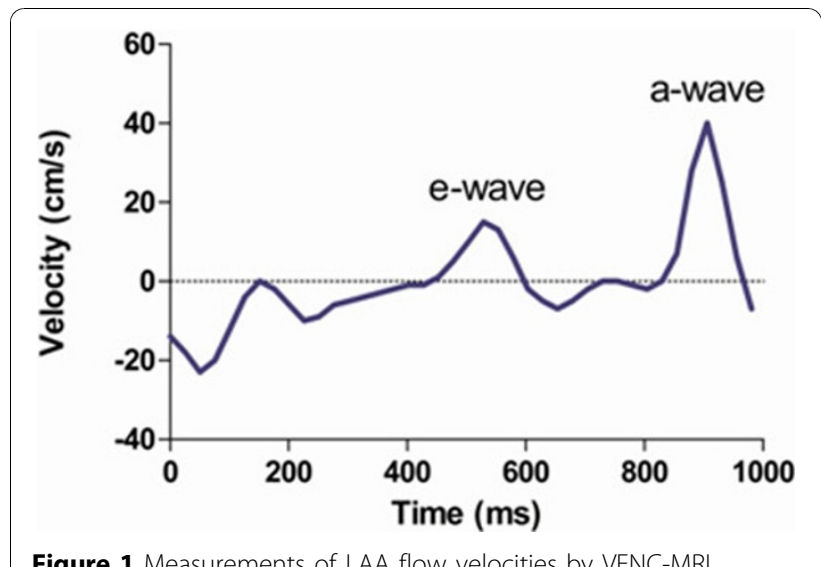


doi:10.1186/1532-429X-13-S1-P252

Cite this article as: Muellerleile et al: Left atrial appendage flow velocities: assessment by velocity encoded magnetic resonance imaging. Journal of Cardiovascular Magnetic Resonance 2011 13(Suppl 1): P252.

Submit your next manuscript to BioMed Central and take full advantage of:

- Convenient online submission

- Thorough peer review

- No space constraints or color figure charges

- Immediate publication on acceptance

- Inclusion in PubMed, CAS, Scopus and Google Scholar

- Research which is freely available for redistribution

Submit your manuscript at www.biomedcentral.com/submit
C Biomed Central 